\title{
Construction of a numerical model of suspension in a numerical simulation of sedimentation
}

\author{
Krzysztof Kołodziejczyk ${ }^{1, *}$ \\ ${ }^{1}$ AGH University of Science and Technology, Mickiewicza 30 Av. 30-059 Krakow, Poland
}

\begin{abstract}
Modeling of multiphase systems, which includes suspensions, is an issue that is continually developed. There are no procedures at the moment that would clearly determine the way in which suspension is defined in numerical simulations. The article presents an analysis of the selection of a numerical model and the definition of the suspension with a polydisperse particle composition.
\end{abstract}

\section{Introduction}

The concept of a multiphase system is very extensive, and shall include both suspensions, i.e., systems comprising a dispersed suspension phase and systems including a liquid in various states of aggregation (e.g. water/steam systems). A system of two not mixed liquids should be regarded as a multiphase (two-phase) too, where a clear boundary allows one to determine the boundary (e.g. air/water systems) [1].

A range of studies on modeling of multiphase systems [2-4] have appeared over the last decade, including studies on the use of numerical methods in the design of slurry settling devices [5].

The largest group consists of models created based on the finite volume method [6] or the method of finite elements [7]. The models that can be divided into two classes: Euler-Lagrang and Euler-Euler. Models belonging to the Euler-Lagrangian Particle Tracking (Discrete Phase Model) class allow the modeling of multi-phase systems with a dispersion phase in a granular form, assuming a low concentration (free sedimentation).

These models are characterized in that in the continuous phase of the liquid, analyzed by the Euler method, the movement of each grain of the disperse phase is calculated using the Lagrangian method. As a result, each grain is individually modeled - this allows one to conduct numerical simulations of suspension where the dispersion phase can have any composition of the particle sizes. This way of defining a multiphase system has a significant limitation resulting from the number of grains of the dispersion phase that we can model. In practice, the dispersion is limited to a few or tens of thousands of grains. Therefore, models of this class will be dedicated to calculations such as the spread of pollutants or tracking particle traces and their propagation rather than modeling of systems in which the concentration of the dispersion phase plays an important role.

\footnotetext{
* Corresponding author: krkolodz@agh.edu.pl
} 
Among the models belonging to the second group (Euler-Euler models), the VOF, Mixture and Eulerian models should be distinguished. In these models, each phase (phase dispersed and continuous) treated as a continuous means described using Euler method. In the calculation area, each of the phases is represented by its volume fraction. Depending on the model, the interactions between the phases are considered differently. Therefore, each model is dedicated to a different group of multi-phase systems or allows to analyze the system in other respects.

In high concentrations, where in one cubic centimeter there can be up to several millions of grains, Euler-Euler class models are used, where the continuous and dispersion phases can be treated as continuous phase with varying degrees of participation by volume.

\section{The choice of the computational model}

By setting out to model a multiphase system, one must assume a fundamental element to determine which class numerical model will be the most suitable one to carry out simulations of interest. As has been mentioned, the currently available models belong to two classes: Euler-Lagrange and Euler-Euler. In the case of numeric methods for modeling the work of a settling device, the basic criterion of choice of the model class will be the share of the dispersion phase.

The analysis of the selection of the model class in a multiphase system was performed for a sample industrial suspension. In the analysis, a suspension of carbon from a coal enrichment plant after stripping coal processing was used. The share of the disperse phase for its initial concentration $\mathrm{s}_{0}=45 \mathrm{~kg} / \mathrm{m}^{3}$ and the density of solid part $\rho_{\mathrm{d}}=2299 \mathrm{~kg} / \mathrm{m}^{3}$ was, according to equation (1), $\varphi_{d}=0.0195$. As the volume of the dispersion fraction is almost $2 \%$, one can classify the sedimentation process which will occur in the suspension as a process of hindered sedimentation [8].

$$
\varphi_{\mathrm{d}}=\frac{\mathrm{s}_{0}}{\rho_{\mathrm{d}}}
$$

An additional criterion that can be used here to calculate the average distance between particles of the disperse phase, which one can determine from the load of suspended particles and density ratio in the phases. The grain load of the suspension is determined from the relationship (2) and is $\beta=0.0459$.

$$
\beta=\frac{\varphi_{\mathrm{d}} \cdot \rho_{\mathrm{d}}}{\varphi_{\mathrm{c}} \cdot \rho_{\mathrm{c}}}
$$

where:

$d \quad-\quad$ index of the disperse phase,

$c \quad-\quad$ index of the continuous phase.

The ratio of the density of the disperse phase and the continuous phase shall be $\gamma=2.299(3)$.

$$
\gamma=\frac{\rho_{\mathrm{d}}}{\rho_{\mathrm{c}}}
$$

Taking into account the above ratios (2) and (3) one can determine the average distance between particles in suspension from the equation:

$$
\frac{L}{d_{d}}=\left(\frac{\pi}{6} \frac{1+\frac{\beta}{\gamma}}{\frac{\beta}{\gamma}}\right)^{\frac{1}{3}}
$$

In the case considered, from the equation (4), we obtain: $L / d_{d}=2.99$. 
If the average distance between the particles is greater than 8 then there is confidence that each grain falls freely, independently of the other grains, and the Lagrangian DPM (Discrete Phase Model) model can be deemed appropriate to describe the motion of the grains. However, in the system where the average distance between particles is less than 8 , one should consider one of the VOF (Volume of Fluid), Mixture or Eulerian models. Since the VOF model allows modeling multiphase systems where both the continuous phase and the dispersion phases are liquid, it cannot be used for modeling the sedimentation of coal slurry.

The Stokes number is a criterion for the use of a Mixture or Eulerian model. It is defined as the product of the reaction time for the particle and the system, where the response time of the particles is calculated from the relationship:

$$
\tau_{\mathrm{d}}=\frac{\rho_{\mathrm{d}} \cdot \mathrm{d}_{\mathrm{d}}^{2}}{18 \cdot \mu_{\mathrm{c}}}
$$

From the equation (5) for grain $\mathrm{d}_{\mathrm{d}}=7.89 \mu \mathrm{m}$ we obtain: $\tau_{\mathrm{d}}=8 * 10^{-6} \mathrm{~s}$, where $\mathrm{d}_{\mathrm{d}}$ is the diameter of the boundary grain.

The response time of the ts system is calculated based on the dominant flow rate and the dimension of the characteristic $\mathrm{L}_{\mathrm{s}}$ system (usually the way from input to output) according to equation:

$$
\mathrm{t}_{\mathrm{s}}=\frac{\mathrm{L}_{\mathrm{s}}}{\mathrm{v}_{\mathrm{s}}}
$$

Ultimately, the Stokes number will be calculated according to (7).

$$
\mathrm{S}_{\mathrm{t}}=\frac{\tau_{\mathrm{d}}}{\mathrm{t}_{\mathrm{s}}}
$$

The limit value of the Stokes number is 1 . For $S<<t$ we can use any model of a multiphase system, and for the St above 1, we shall use the DPM or Eulerian model.

In the case of modeling static sedimentation, a system without flow is analyzed, therefore, the dominant component will be the movement of particles of the disperse phase, thus making the Eulerian a more appropriate model to describe the process of static sedimentation. Due to the volume fraction of the disperse phase, the DPM model cannot be used.

In the case of modeling the operation of a settler, where flow occurs, the Stokes number will depend on the zone of sedimentation for which it will be calculated. In the refining zone the flow rate is normally greater than the rate of sedimentation, thus the Stokes number will have a value less than 1. In turn, in the layer of sludge, flow rate will tend to zero, which in turn will result in a Stokes number greater than 1 . As a result, one can draw a conclusion that the most appropriate model for use in numerical simulations of a settler operation will be an Eulerian model.

\section{Numerical model of a multiphase system}

The Eulerian model, used to model multi-phase systems, allow the implementation of the simulation in which there is one main phase (solid) and at least one disperse phase. In this model, there is no limit to the number of dispersion phases beyond the limits of hardware consisting in the availability of memory and computing power. The Eulerian model, among all models of multiphase systems, is the one with the greatest demand for computing power and RAM. However, it is a model that offers the widest possibilities when calculating the interaction between the phases.

A characteristic feature of this model is that for each phase, a continuity equation and a momentum equation are solved. In this model, it is assumed that the pressure at any point is the same for all phases. Other sizes are calculated individually for each phase. In this 
model, it is possible to take account of various types of inter-phase interactions as well as calculation of flow by one of the turbulence models for the various phases.

Phases of the Eulerian model are treated as interpenetrating continua, representing a multiphase system, in which each phase has its share of the volume described as $\varphi_{\mathrm{q}}$, where the total volume of shares of the various phases in the whole system is 1 .

As a result, in Euler-Euler class models, a system of equations is solved to describe the flow. In numerical calculations, the same material with different physical properties, e.g. the diameter of grains [9] should also be considered a separate phase. Due to the fact that the disperse fraction in this model may be composed of grains of a specified diameter, it is possible to obtain multiple system by building several dispersion phases with varying grain composition. However, this results in multiplication of the number of equations that must be solved for such a system. The main advantage of this model is that it can be used in the full range of shares by volume of each phase [3].

In Eulerian class models, the balance of the q phase for a multiphase mixture [3] is described by the equation (8).

$$
\frac{\partial}{\partial \mathrm{t}}\left(\varphi_{\mathrm{q}} \rho_{\mathrm{q}}\right)+\nabla\left(\varphi_{\mathrm{q}} \rho_{\mathrm{q}} \overrightarrow{\mathrm{v}}_{\mathrm{q}}\right)=\sum_{\mathrm{p}=1}^{\mathrm{n}}\left(\dot{\mathrm{m}}_{\mathrm{pq}}-\dot{\mathrm{m}}_{\mathrm{qp}}\right)+\mathrm{S}_{\mathrm{q}}
$$

where:

$$
\begin{array}{cll}
\varphi_{q} & - & \text { volume share of phase } \mathrm{q}, \\
\vec{v}_{q} & - & \text { velocity of phase } \mathrm{q}, \\
\rho_{q} & - & \text { density of phase } \mathrm{q}, \\
\dot{m}_{p q} & - & \text { mass flow between } \mathrm{p} \text { and } \mathrm{q} \text { phases }=1,2,3, \ldots, \mathrm{n}, \\
S_{q} & - & \text { additional (external) source of mass for phase } \mathrm{q}, \text { variable or constant. }
\end{array}
$$

When the sum of the volume of the individual phases of 1 (9)is maintained.

$$
\sum_{\mathrm{q}=1}^{\mathrm{n}} \varphi_{\mathrm{q}}=1
$$

The equation of the velocity balance for the q phase mixture in an Eulerian model is described by the vector equation:

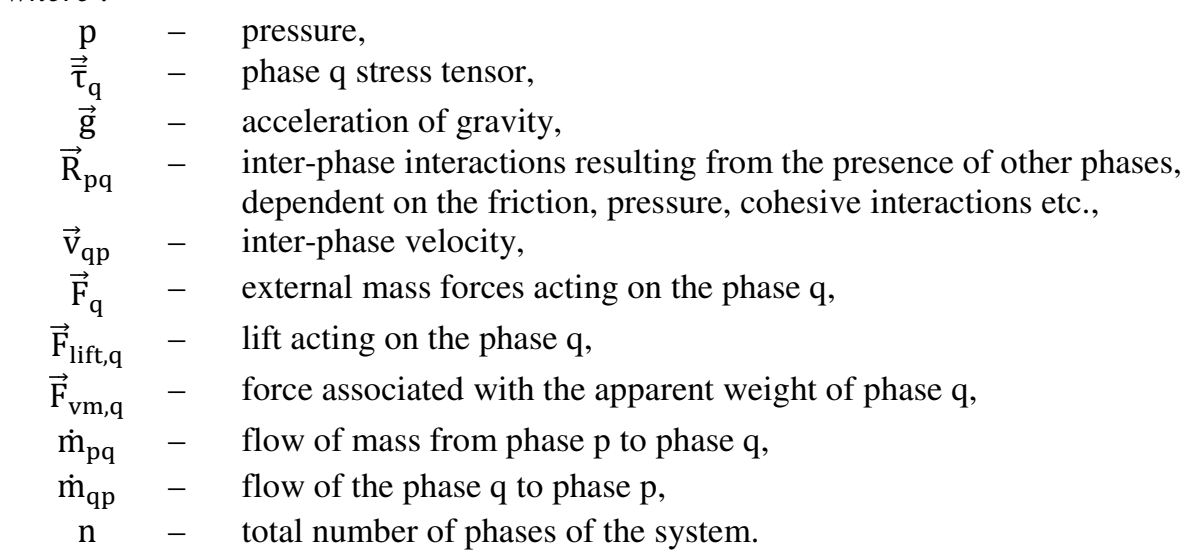


In the calculation of a multiphase system for each phase, a set of equations set forth above is solved. In the case of computation for the range of a turbulence model, the equations are supplemented with the equations describing the turbulence. In effect, the modeling of a multiphase system using several dispersion phases results in a very high demand for computing power and a very long calculation times.

The continuity equation for one fraction, assuming no mass transfer between the phases and a lack of sources of weight will be described by the equation (11).

$$
\frac{\partial}{\partial \mathrm{t}}\left(\varphi_{\mathrm{q}} \rho_{\mathrm{q}}\right)+\nabla\left(\varphi_{\mathrm{q}} \rho_{\mathrm{q}} \overrightarrow{\mathrm{v}}_{\mathrm{q}}\right)=0
$$

The sum of the volume shares of each volume fraction $\varphi q$ must equal 1 according to equation (10).

In addition, for incompressible fluids, the continuity equation (11) will have the form:

$$
\sum_{\mathrm{q}} \nabla\left(\varphi_{\mathrm{q}} \overrightarrow{\mathrm{v}}_{\mathrm{q}}\right)=0
$$

The equation for fluid is described by the dependency (13).

$$
\begin{aligned}
\frac{\partial}{\partial \mathrm{t}}\left(\varphi_{\mathrm{q}} \rho_{\mathrm{q}} \overrightarrow{\mathrm{v}}_{\mathrm{q}}\right)+\nabla & \left(\varphi_{\mathrm{q}} \rho_{\mathrm{q}} \overrightarrow{\mathrm{v}}_{\mathrm{q}} \overrightarrow{\mathrm{v}}_{\mathrm{q}}\right) \\
= & -\varphi_{\mathrm{q}} \nabla \mathrm{p}_{\mathrm{q}}+\nabla \cdot \overrightarrow{\bar{\tau}}_{\mathrm{q}}+\varphi_{\mathrm{q}} \rho_{\mathrm{q}} \overrightarrow{\mathrm{g}}+\sum_{\mathrm{p}=1}^{\mathrm{n}}\left(\overrightarrow{\mathrm{R}}_{\mathrm{pq}}\right) \\
& +\left(\overrightarrow{\mathrm{F}}_{\mathrm{q}}+\overrightarrow{\mathrm{F}}_{\text {lift }, \mathrm{q}}+\overrightarrow{\mathrm{F}}_{\mathrm{vm}, \mathrm{q}}\right)
\end{aligned}
$$

The forces acting on the phase of the $\mathrm{q}$, as a result of the presence of other phases, are described by the equation (14).

$$
\overrightarrow{\mathrm{R}}_{\mathrm{pq}}=\mathrm{c}_{\mathrm{pq}}\left(\overrightarrow{\mathrm{v}}_{\mathrm{p}}-\overrightarrow{\mathrm{v}}_{\mathrm{q}}\right)
$$

The rate $\mathrm{c}_{\mathrm{pq}}$ is described by the formula (15).

$$
c_{p q}=\frac{C_{D}}{8} A_{p q} \rho_{q}\left|\vec{v}_{p}-\vec{v}_{q}\right|
$$

where the resistance coefficient $\mathrm{CD}$ will depend on the Reynolds number calculated from one of the equations (16) or (17):

$$
\begin{gathered}
C_{D}=\frac{24}{R e} \text { for } \operatorname{Re}<<1 \\
C_{D}=0,44 \text { for } 1000 \leq \operatorname{Re} \leq 1 \div 2 \times 105
\end{gathered}
$$

For Reynolds numbers in the range $0.1<\operatorname{Re}<1000$, it can be designated using one of the models:

The Schiller Naumann Drag Model (18) [10] - dedicated for calculations of multiphase systems with a low share dispersion phase.

$$
C_{D}=\frac{24}{\operatorname{Re}}\left(1+0,15 \operatorname{Re}^{0,687}\right)
$$

Wen Yu Drag Model (19) [11].

$$
\begin{gathered}
\mathrm{C}_{\mathrm{D}}=\varphi_{\mathrm{c}}^{-1,65} \max \left(\frac{24}{\operatorname{Re}^{\prime}}\left(1+0,15 \operatorname{Re}^{0,687}\right) ; 0,44\right) \\
\operatorname{Re}^{\prime}=\varphi_{\mathrm{c}} \operatorname{Re}
\end{gathered}
$$

where :

$\varphi_{\mathrm{c}} \quad-\quad$ volume of the continuous phase. 
Gidaspow Drag Model (20)[12].

$$
\begin{gathered}
C_{D}=C_{D}(\text { Wen Yu }), \varphi_{c}>0,8 \\
c_{p q}=150 \frac{\left(1-\varphi_{c}\right)^{2} \mu_{c}}{\varphi_{c} d_{p}^{2}}+\frac{7}{4} \frac{\left(1-\varphi_{c}\right) \rho_{c}\left|\vec{v}_{c}-\vec{v}_{d}\right|}{d_{p}} ; \varphi_{c}<0,8
\end{gathered}
$$

\section{Definition of the numerical model of a grain composition of the polydisperse suspension}

In real life systems, except in individual cases, suspensions with polydisperse grain composition occur [13]. An example of a grain composition described by a particle size distribution curve is presented in Figure 1. The use of particle size distribution described using a graph in numerical calculations would be very cumbersome, since in practice the grain composition is described using a random variable. The distribution of particle sizes most commonly used here is the log normal parameter distribution with two parameters: $\mathrm{m}$ and sigma. In numerical simulations of the process of sedimentation, a fully polydisperse size distribution can be defined only in Euler-Lagrangian class models, i.e., in the case of free sedimentation with low concentration slurries.

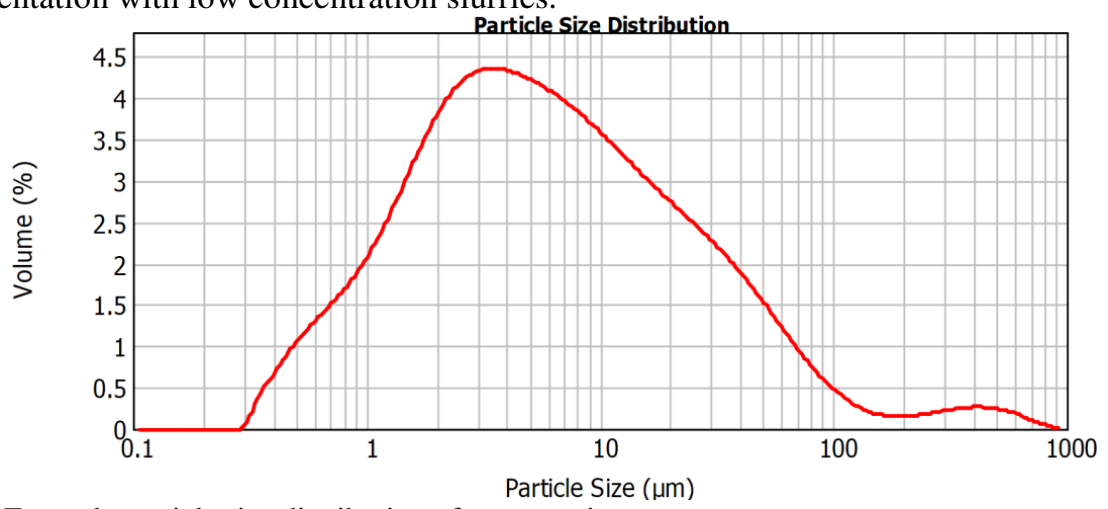

Fig. 1. Example particle size distribution of a suspension

In sedimentary systems, where Euler-Euler class models are used, the dispersion fraction is defined as a separate phase or a set of phases, each with a defined volume share and a defined particle size. Tests modeling the sedimentation using a monodisperse particle size distribution fraction have not provided satisfactory results. The studies and analyses carried out so far [14] indicate that defining a dispersion fraction based on a particle size distribution described by a histogram comprising several grain classes is the solution that gives promising results. An example of a particle size distribution in a slurry described by grain sizes is presented in table 1 .

Table 1. An example of grain composition described using grain classes

\begin{tabular}{|c|c|c|}
\hline $\begin{array}{c}\text { Grain class } \\
\mu \mathrm{m}\end{array}$ & $\begin{array}{c}\text { Representative } \\
\text { grain diameter } \\
\mu \mathrm{m}\end{array}$ & $\begin{array}{c}\text { Share } \\
\%\end{array}$ \\
\hline $0 \div 2$ & 1.0 & 17.9 \\
\hline $2 \div 5$ & 3.5 & 20.1 \\
\hline $5 \div 12$ & 8.5 & 23.0 \\
\hline $12 \div 30$ & 21.0 & 20.4 \\
\hline$>30$ & 60.0 & 18.6 \\
\hline
\end{tabular}


Based on the analysis carried out [14], it should be noted that in numerical simulations of the polydispersity dispersion, the use of the monodisperse numerical suspension model with substitution parameters does not produce positive results, therefore it is necessary to use multiphase systems in numerical simulations. The presented method of defining a multiphase system based on the grain composition of the suspension allows obtaining near-laboratory results of sedimentation in numerical simulations, with a change in the concentration of the suspension at the overflow and outflow, including the change in grain composition at the overflow and outflow.

\section{Conclusion}

The analysis shows that taking into consideration the purpose of conducting numerical simulations of sedimentation, i.e., to obtain a concentration distribution in a settler, numerical simulations of settling device operation should use Euler-Euler class models. These models allow you to obtain information on the volume share of the individual fractions (the main and dispersion fraction), which is, in effect, the distribution of the concentrations of the suspension in the device. As a result of the analysis, it should be noted that the most appropriate model for numerical simulation of sedimentation will be the Eulerian model. At the same time, it should be noted that there is a necessity of further work to determine the number of grain fractions sufficient to conduct reliable simulations, burdened an error of no more than a few percent.

\section{References}

1. W. P. Kowalski, Osadniki wielostrumieniowe. Kraków: AGH (2004)

2. A. Prosperetti i G. Tryggvason, Computational Methods for Multiphase Flow, $1^{\text {st }}$ edition. Cambridge ; New York: Cambridge University Press (2009)

3. B. Gicala, Modelowanie numeryczne przepływów wielofazowych z fazą dyspersyjną. Podstawy teoretyczne i zastosowanie. Gliwice: Instytut Techniki Górniczej KOMAG (2011)

4. G. Tryggvason, R. Scardovelli, i S. Zaleski, Direct Numerical Simulations of Gas-Liquid Multiphase Flows. Cambridge, UK ; New York, NY: Cambridge University Press (2011)

5. S. Berres, R. Bürger, i E. M. Tory, „Applications of polydisperse sedimentation models”, Chem. Eng. J., 111, nr 2-3, pp. 105-117, (2005)

6. R. Eymard, T. Gallouët, i R. Herbin, „Finite volume methods”, 7, B.-H. of N. Analysis, Red. Elsevier, pp. 713-1018, (2000)

7. O. C. Zienkiewicz, R. L. Taylor, i R. L. Taylor, The finite element method, t. 3. McGrawhill London (1977)

8. J. Bandrowski, H. Merta, i J. Zioło, Sedymentacja zawiesin: zasady i projektowanie. Gliwice: Politechnika Śląska (2001)

9. M. Banas, „The dependence of sedimentation efficiency on susupension concentration”, Inzynieria Chem. Proces., 25, 3, p. 659-664, (2004)

10. L. Schiller i A. Naumann, VDI Zeits, t. 77. (1933)

11. C. Y. Wen i Y. H. Yu, ,Mechanics of Fluidization”, Chem Eng Prog Symp, 62, pp. 100$111,(1966)$

12. D. GIDASPOW, Multiphase Flow and Fluidization. San Diego: Academic Press (1994)

13. M. Banas, P. Warzecha, i B. Hilger, „DISTRIBUTION OF TURBIDITY IN THE WATER TREATMENT PLANT SETTLER", 14th SGEM GeoConference on Ecology, Economics, Education And Legislation, 2, pp. 193-200 (2014) 
14. K. Kołodziejczyk, „Projektowanie osadnika wielostrumieniowego z zastosowaniem numerycznej symulacji przepływu”, Przem. Chem., 96, 8, (2017) 